\title{
Dissolved oxygen detection by galvanic displacement-induced graphene/silver nanocomposite
}

\author{
LI FU $^{1,2, *}$, YUHONG ZHENG ${ }^{1}$, ZHUXIAN FU ${ }^{2}$, AIWU WANG ${ }^{3}$ and WEN CAI ${ }^{3}$ \\ ${ }^{1}$ Institute of Botany, Jiangsu Province and Chinese Academy of Sciences, Nanjing Botanical Garden, Mem. Sun Yat-Sen, \\ Nanjing 210014, PR China \\ ${ }^{2}$ Golden Yuanta Construction Engineering Co., Ltd., Zhejiang 311200, PR China \\ ${ }^{3}$ Department of Physics and Materials Science, City University of Hong Kong, Tat Chee Avenue, Hong Kong
}

MS received 12 September 2014; revised 6 November 2014

\begin{abstract}
This paper proposed a simple, efficient and sensitive electrochemical sensor for dissolved oxygen (DO) detection based on a galvanic displacement synthesized reduced graphene oxide-silver nanoparticles (RGO/Ag) composite modified grassy carbon electrode (GCE). The synthesized RGO/Ag nanocomposite was characterized by UV-vis spectroscopy, Raman spectroscopy, scanning electron microscopy (SEM) and X-ray diffraction (XRD). The results indicate the graphene oxide (GO) has been successfully reduced during the galvanic displacement process and the average size of Ag nanoparticle is $52 \mathrm{~nm}$. The RGO/Ag nanocomposite-modified GCE showed a significant enhancement of DO detection compared with bare and RGO-modified GCEs. Moreover, the proposed DO sensor also exhibited an excellent repeatability, reproducibility and anti-interference ability.
\end{abstract}

Keywords. Nanocomposite; graphene; dissolved oxygen; sensor.

\section{Introduction}

Oxygen reduction reaction has been of great importance in many fields such as food industry, fuel cells, batteries, metal corrosion, bioscience and biotechnology. For example, dissolved oxygen (DO) is an indicator of water quality. Furthermore, careful controlling and monitoring the oxygen level also play an important role in the food industry and clinical analyses. Thus, the evaluation of the amount of DO in aqueous systems is essential for many fields. Up to now, several methods have been developed for DO detection such as titration, ${ }^{1}$ colorimetry, ${ }^{2}$ fluorescence, ${ }^{3}$ chemiluminescence $^{4}$ and electrochemical sensor. ${ }^{5-9}$ Among these analytic approaches, the electrochemical sensor has received lots of attention due to its fast speed, low cost, low detection limit and high accuracy. However, direct detection of DO at commercial electrode needs a high potential. Therefore, many different methods have been developed for electrode surface modification and improving electrons transfer efficiency between DO and electrode surface. Rahim et al demonstrated a DO sensor based on the electrode modified by cobalt (II) phthalocyanine immobilized carbon ceramic mesoporous $\mathrm{SiO}_{2} / \mathrm{C}$.

Graphene, a newly developed form of carbon, has attracted increasing attention in recent times due to its unique physical and electrochemical properties. In electrochemistry field,

\footnotetext{
*Author for correspondence (lifugyt@gmail.com)
}

using graphene as modifier showed potential advantages of high surface area, ease of processing and safety..$^{10}$ Besides, graphene has a large theoretical surface area $\left(2630 \mathrm{~m}^{2} \mathrm{~g}^{-1}\right)$ and superior electrical conductance $\left(64 \mathrm{mS} \mathrm{cm}^{-1}\right){ }^{11,12}$ Moreover, graphene also exhibits a large potential window, low charge-transfer resistance and fast electron transfer rate. Many reports also pointed out that graphene could enhance the electrocatalytic performance of noble metal nanoparticles. ${ }^{13,14}$ In recent times, as a typical nanomaterial, silver nanostructures are also studied for detecting DO. ${ }^{9}$ Therefore, attempting to combine the graphene with $\mathrm{Ag}$ nanoparticles is expected to generate a suitable electrode material for DO sensing application.

In this context, we report the development of a DO sensor based on the galvanic displacement-induced reduced graphene oxide/silver nanocomposite (RGO/Ag). The RGO/Ag nanocomposite was characterized by UV-vis spectroscopy, Raman spectroscopy, scanning electron microscopy (SEM) and X-ray diffraction (XRD). RGO/Ag nanocompositemodified glassy carbon electrode (GCE) was then fabricated for DO determination.

\section{Experimental}

\subsection{Materials}

$\mathrm{AgNO}_{3}$, uric acid (UA), 3-hydroxytyramine hydrochloride (DA) and glucose were purchased from Sigma-Aldrich. Graphene oxide powder was purchased from JCNANO, Inc. All other chemicals used were analytical grade reagents 
without further purification. The $\mathrm{O}_{2}$-saturated phosphate buffer solution (PBS) was produced by bubbling PBS with $\mathrm{O}_{2}$ gas for $15 \mathrm{~min}$, in which the DO concentration was $250 \mu \mathrm{M}$. Milli-Q water $(18.2 \mathrm{M} \Omega \mathrm{cm})$ was used throughout the experiment.

\subsection{Synthesis of RGO/Ag nanocomposite}

$\mathrm{RGO} / \mathrm{Ag}$ nanocomposite was prepared via the galvanic displacement method. In a typical experiment, $10 \mathrm{ml}$ of $\mathrm{AgNO}_{3}$ solution $(20 \mathrm{mM})$ was firstly mixed with $2 \mathrm{ml}$ of graphene oxide (GO) dispersion $\left(1 \mathrm{mg} \mathrm{ml}^{-1}\right)$ under vigorous stirring. Then, a piece of $\mathrm{Cu}$ foil $(1 \mathrm{~cm} \times 1 \mathrm{~cm})$ was polished with sandpaper and then immersed into the mixture. Then, the solution was transferred to a Teflon-lined stainless-steel autoclave. The autoclave was heated to $120^{\circ} \mathrm{C}$ and maintained for $2 \mathrm{~h}$ in an oven, after that it was naturally cooled down to the room temperature. Gray sediment was collected and centrifuged to obtain $\mathrm{RGO} / \mathrm{Ag}$ nanocomposite.

\subsection{Characterization}

The morphology and crystal formation of the RGO-Ag nanocomposite were characterized using a scanning electron microscope (SEM, S-4700, Hitachi High Technologies Corporation, Japan) and a X-ray diffractometer (D8-Advance XRD, Bruker, Germany) with $\mathrm{Cu} \mathrm{K} \alpha$ radiation, respectively. Raman spectroscopy was performed at room temperature using a Raman Microprobe (Renishaw RM1000) with 514 nm laser light. For electrochemical experiments, a GCE was polished with alumina-water slurry followed by rinsing with ethanol and water. For the electrode surface modification, $5 \mu \mathrm{l}$ of catalyst dispersion $\left(1 \mathrm{mg} \mathrm{ml}^{-1}\right)$ was dropped onto the GCE and dried at room temperature. Electrochemical measurements were performed on a $\mathrm{CH}$ Instruments 660A electrochemical Workstation (CHI-660 A, CH Instruments, Texas, USA) using a three-electrode system. A platinum wire was used as the auxiliary electrode and an $\mathrm{Ag} / \mathrm{AgCl}$ ( $3 \mathrm{M} \mathrm{KCl}$ ) as the reference electrode. The specific DO concentration in the cell was controlled by using $\mathrm{N}_{2}$ bubbling with different time intervals. The DO concentration was monitored during the whole experiment by using the dissolved oxygen meter.

\section{Results and discussion}

Figure 1a shows the SEM image of the synthesized RGO/Ag nanocomposite. It can be clearly seen that the $\mathrm{RGO} / \mathrm{Ag}$ nanocomposite was successfully synthesized via the galvanic displacement. The RGO sheets show a corrugated structure. The $\mathrm{Ag}$ nanoparticles are decorated on the both sides of RGO sheet, which could effectively prevent the stacking of RGO sheets. ${ }^{15}$ Figure $1 \mathrm{~b}$ displays the size distribution of $\mathrm{Ag}$ nanoparticles. The average size of Ag nanoparticle formed via the galvanic displacement is calculated as $52 \mathrm{~nm}$. EDX analysis was conducted to obtain elements information about $\mathrm{RGO} / \mathrm{Ag}$ nanocomposite (figure $2 \mathrm{a}$ ). The spectrum presents the existence of $\mathrm{C}, \mathrm{O}, \mathrm{Ag}$ and $\mathrm{Cu}$. The EDX measurement also shows that the $\mathrm{Ag}$ loading of $\mathrm{RGO} / \mathrm{Ag}$ nanocomposite is about $70.57 \%$.

The reduction of GO and formation of Ag were confirmed by UV-vis spectroscopy. Figure $2 \mathrm{~b}$ displays the UV-vis spectra of GO and RGO/Ag nanocomposite. The spectrum of GO displays a characteristic peak at $236 \mathrm{~nm}$ corresponding to the $\pi \rightarrow \pi^{*}$ transition of the $\mathrm{C}=\mathrm{C}$ bonds, while the $\mathrm{RGO} / \mathrm{Ag}$ nanocomposite shows a peak at $259 \mathrm{~nm}$ corresponding to the excitation of $\pi$-plasmon of graphitic bond. ${ }^{16}$ This red-shift indicates the reduction of GO during the galvanic displacement. Moreover, a clear broad absorption peak located at $385 \mathrm{~nm}$ was observed in the spectrum of RGO/Ag nanocomposite due to the surface plasmon resonance absorption of $\mathrm{Ag}$ nanoparticles.

The reduction of GO was also confirmed by the Raman spectroscopy. As shown in figure 3, the spectrum of GO exhibits two characteristic bands at 1572 and $1335 \mathrm{~cm}^{-1}$, which was assigned to the graphite (the $\mathrm{G}$ band, first-order scattering of $E_{2 \mathrm{~g}}$ phonons by $\mathrm{sp}^{2}$ carbon atoms) and diamondoid (the D band, breathing mode of $\kappa$-point photons of $\mathrm{A}_{1 \mathrm{~g}}$ symmetry) bands, respectively. ${ }^{17}$ The intensity ratio between the $\mathrm{D}$ band and the $\mathrm{G}$ band $\left(I_{\mathrm{D}} / I_{\mathrm{G}}\right)$ increases from
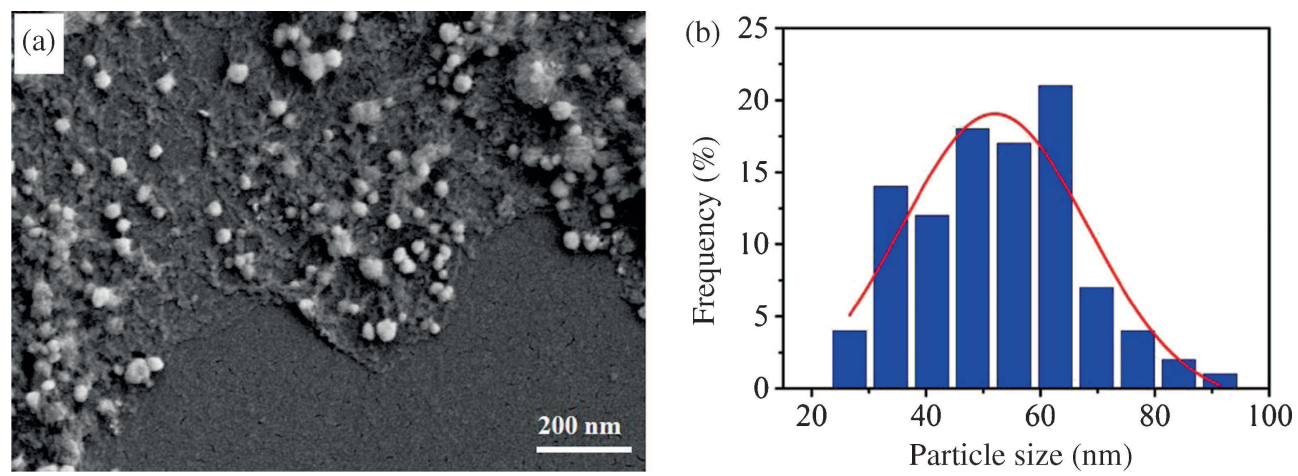

Figure 1. (a) SEM image of RGO/Ag nanocomposite and (b) particle size distribution of $\mathrm{Ag}$ nanoparticles. 

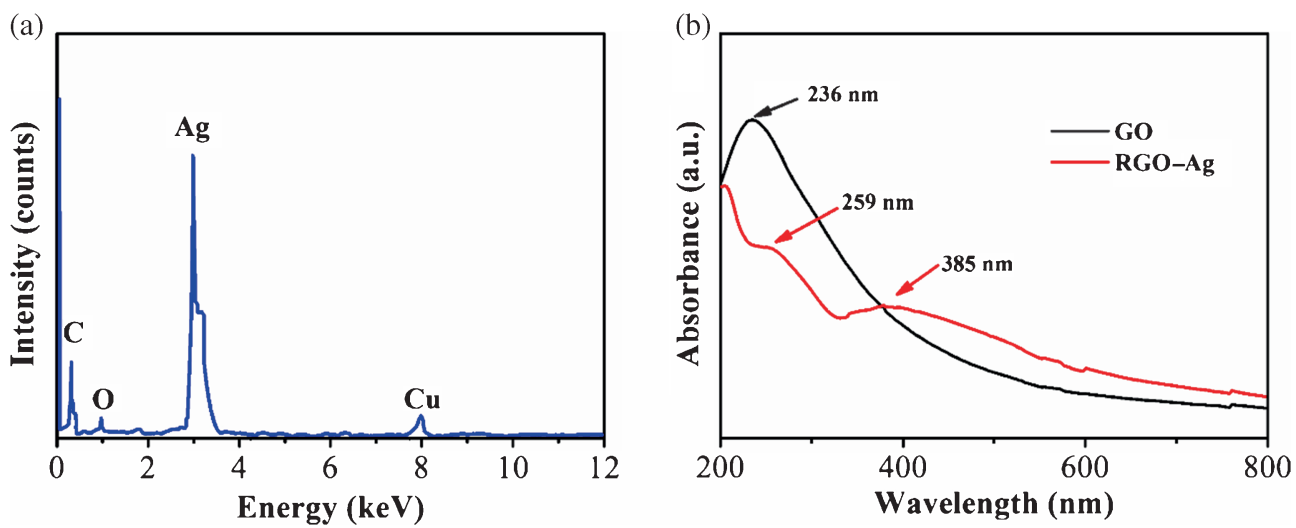

Figure 2. (a) EDX spectrum of RGO/Ag nanocomposite and (b) UV-vis spectra of GO and RGO/Ag nanocomposite.

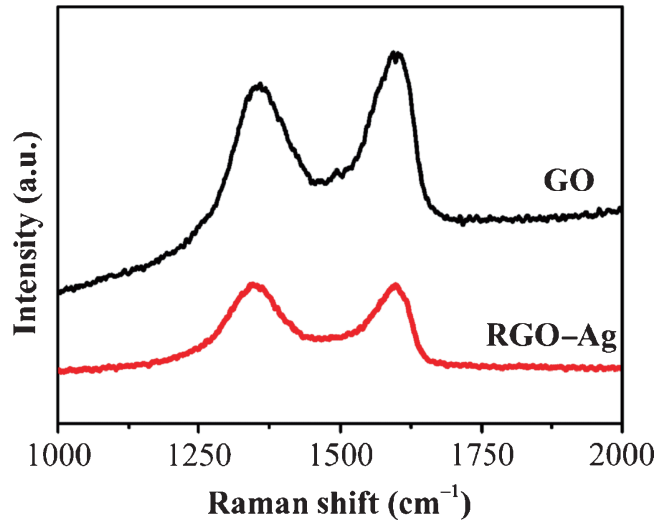

Figure 3. Raman spectra of $\mathrm{GO}$ and $\mathrm{RGO} / \mathrm{Ag}$ nanocomposite.

0.92 in $\mathrm{GO}$ to 1.09 in $\mathrm{RGO} / \mathrm{Ag}$ nanocomposite, which is due to the decrease of average size of $\mathrm{sp}^{2}$ domains by reduction of GO. ${ }^{18}$

Figure 4 presents the XRD pattern of galvanic displacement synthesized RGO/Ag nanocomposite. As shown in the figure, the diffraction peaks at $36.41^{\circ}, 42.67^{\circ}, 62.93^{\circ}$ and $75.91^{\circ}$ are assigned to the (200), (220), (311) and (222) silver face-centred-cube (fcc) crystal diffractions (JCPDS file no. 04-0783), respectively. Besides Ag peaks, additional peak appears at $26.2^{\circ}$, which is ascribed to the partial RGO sheets restacking into an ordered crystalline structure. ${ }^{19}$

Figure 5 gives a comparison among the cyclic voltammograms (CVs) of bare, RGO and RGO/Ag nanocompositemodified GCEs in $0.1 \mathrm{M} \mathrm{N}_{2}$ saturated PBS. No obvious redox peaks were observed for the bare and RGO-modified GCEs. However, the RGO-modified GCE showed a much higher current response over the scan range, indicating the RGOmodified GCE owned a larger surface area. In contrast, a well-defined redox peak was observed for RGO/Ag nanocomposite-modified GCE with the anodic peak potential at $0.47 \mathrm{~V}$ and the cathodic peak potential at $0.07 \mathrm{~V}$, which correspond to the one-electron redox process of $\mathrm{Ag}$ nanoparticles. ${ }^{20,21}$

The electrochemical performance of the RGO/Ag nanocomposite towards detecting DO was investigated.

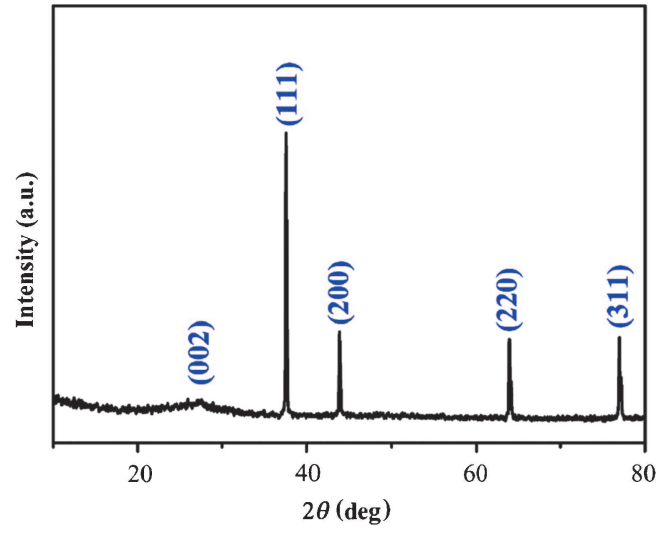

Figure 4. XRD pattern of RGO/Ag nanocomposite.

Figure 6 displays the cyclic voltammograms (CVs) of bare, $\mathrm{RGO}$ and $\mathrm{RGO} / \mathrm{Ag}$ nanocomposite-modified GCEs in $\mathrm{pH}$ 7.0 PBS with the absence and the presence of saturated $\mathrm{O}_{2}$. It can be seen that no electrode response was observed for $\mathrm{RGO} / \mathrm{Ag}$ nanocomposite-modified GCE with the absence of $\mathrm{O}_{2}$. However, in the presence of $250 \mu \mathrm{M}$ DO, welldefined reduction peaks were observed on the bare, RGO and RGO/Ag nanocomposite-modified GCEs with reduction potential at $-0.62,-0.53$ and $-0.26 \mathrm{~V}$, respectively. Moreover, it illustrated a significant current enhancement on the RGO/Ag nanocomposite-modified GCE. The increasing peak current and lowering peak potential indicate that $\mathrm{RGO} / \mathrm{Ag}$ nanocomposite can effectively catalyse the electrochemical reduction of DO due to a synergistic effect. The RGO sheets not only serve as an excellent electron transfer mediator, but also act as a platform for Ag nanoparticle leading to their enhanced catalytic performance.

The mechanism of oxygen reduction usually involves two steps and four electrons. ${ }^{22}$ The first step is the reduction of $\mathrm{O}_{2}$ to $\mathrm{H}_{2} \mathrm{O}_{2}$ and $\mathrm{OH}^{-}$. The second step is the reduction of $\mathrm{H}_{2} \mathrm{O}_{2}$ to $\mathrm{OH}^{-}$. The formula can be expressed as follows:

$$
\begin{aligned}
& \mathrm{O}_{2}+2 \mathrm{H}_{2} \mathrm{O}+2 \mathrm{e}^{-} \rightarrow \mathrm{H}_{2} \mathrm{O}_{2}+2 \mathrm{OH}^{-}, \\
& \mathrm{H}_{2} \mathrm{O}_{2}+2 \mathrm{e}^{-} \rightarrow 2 \mathrm{OH}^{-} .
\end{aligned}
$$




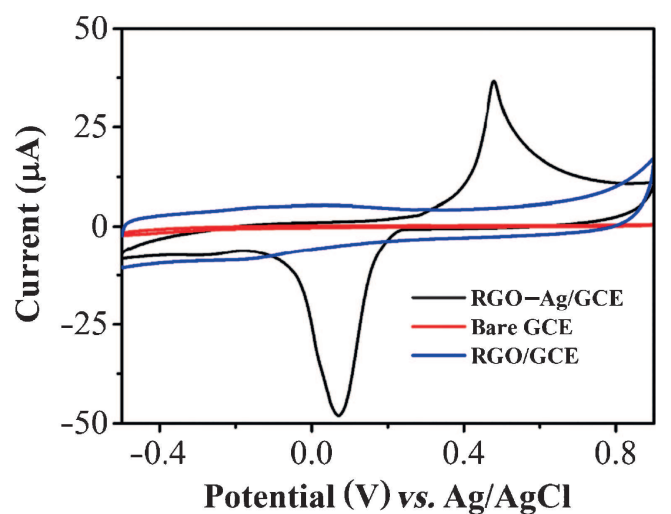

Figure 5. Cyclic voltammograms of bare, RGO- and RGO/Agmodified GCE in $\mathrm{N}_{2}$ saturated PBS. Scan rate $50 \mathrm{mV} \mathrm{s}^{-1}$.

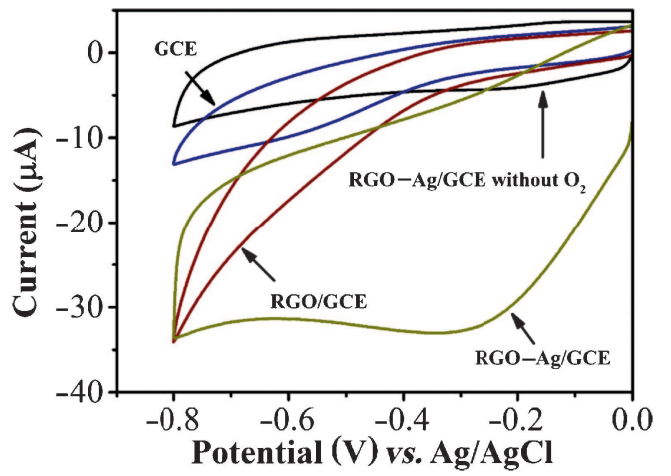

Figure 6. Cyclic voltammograms of bare, RGO- and RGO/Agmodified GCE in $\mathrm{O}_{2}$-saturated or normal PBS. Scan rate $50 \mathrm{mV} \mathrm{s}^{-1}$.

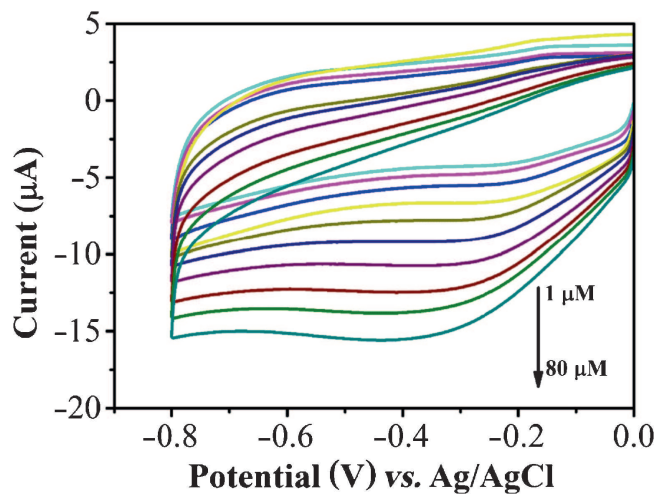

Figure 7. Cyclic voltammograms of RGO/Ag-modified GCE in PBS for different DO concentrations (from the top 1, 5, 10, 20, 30, $40,50,60,70$ and $80 \mu \mathrm{M})$. Scan rate $50 \mathrm{mV} \mathrm{s}^{-1}$.

However, only one sharp reduction peak was observed on the $\mathrm{RGO} / \mathrm{Ag}$ nanocomposite-modified GCE. It indicates a fast and efficient four electrons reaction of DO reduction that occurred on RGO/Ag nanocomposite-modified GCE, which is consistent with that of other silver-based material modified electrode reported previously. ${ }^{9,23,24}$ The formula can be expressed as follows:

$$
\mathrm{O}_{2}+2 \mathrm{H}_{2} \mathrm{O}+4 \mathrm{e}^{-} \rightarrow 4 \mathrm{OH}^{-} .
$$

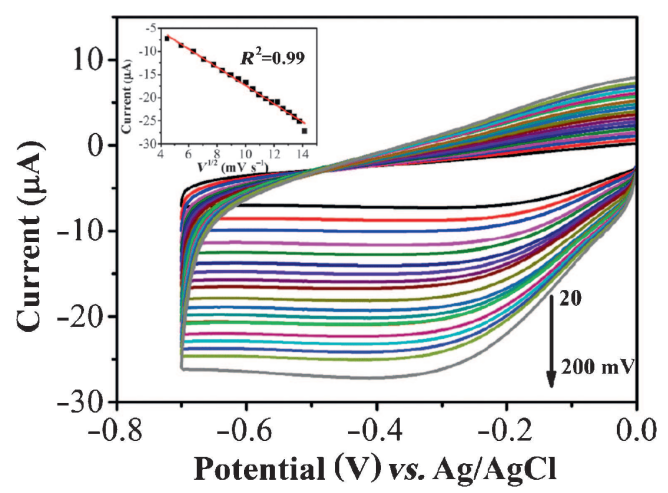

Figure 8. Cyclic voltammograms of the RGO/Ag-modified GCE at scan rate of $20-200 \mathrm{mV} \mathrm{s}^{-1}$ in PBS containing $50 \mu \mathrm{M}$ DO. Inset: plots of peak current $v s$. the square root of the scan rate.

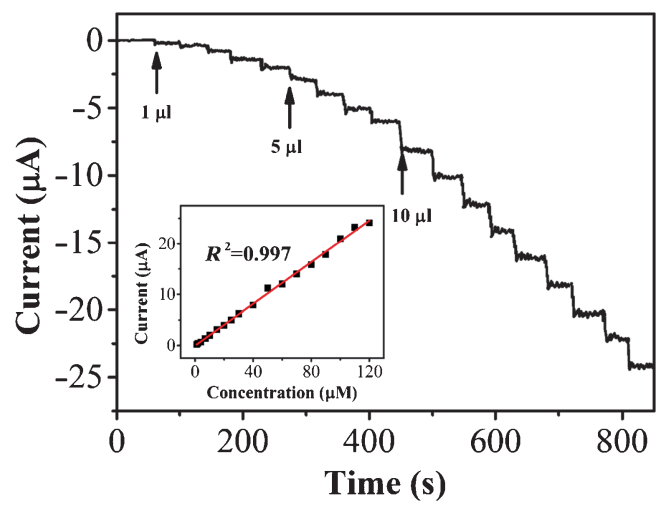

Figure 9. Amperometric response of the RGO/Ag-modified GCE with different concentrations of DO in PBS. Measured at $0.3 \mathrm{~V}$. Inset: calibration curve at a concentration range of 0-120 $\mu \mathrm{m}$.

The electrocatalytic activity of $\mathrm{RGO} / \mathrm{Ag}$ nanocompositemodified GCE for various DO concentrations was then evaluated and is as shown in figure 7. It can be clearly seen that the electrocatalytic current responses gradually increase along with the increment of DO concentration in the range from 1 to $80 \mu \mathrm{M}$.

In order to further understand the electrochemical behaviour of proposed DO sensor, RGO/Ag-modified GCE was examined to investigate the relationship between the peak current and the scan rate. Figure 8 shows the CVs of $\mathrm{RGO} / \mathrm{Ag}$ nanocomposite-modified GCE in $0.1 \mathrm{M}$ PBS containing $50 \mu \mathrm{M}$ DO by controlling the scan rate from 20 to $200 \mathrm{mV} \mathrm{s}^{-1}$. As shown in figure 8, the reduction peak current increase with the increase of the scan rate. The current responses also been found linearly dependent on the square root of scan rate from 20 to $200 \mathrm{mV} \mathrm{s}^{-1}$ (inset of figure 8), indicating that the reduction of DO at electrode surface is controlled by diffusion. The corresponding linear regression can be expressed as $I_{\mathrm{pa}}(\mu \mathrm{A})=-1.96777 v^{1 / 2}$ $\left(\mathrm{mV} \mathrm{s}^{-1}\right)^{1 / 2}+2.31904\left(R^{2}=0.991\right)$.

Amperometric measurements were performed in a PBS at applied potential of $-0.26 \mathrm{~V}$ for DO determination. Figure 9 shows the typical amperometric response upon successive 
Table 1. Comparison of different electrochemical sensors for the determination of DO.

\begin{tabular}{|c|c|c|c|c|}
\hline Electrode & Method & Sensitivity $\left(\mu \mathrm{A} \mu \mathrm{M}^{-1}\right)$ & Detection limit $(\mu \mathrm{M})$ & Reference \\
\hline Silver nanodendrites/GCE & $\mathrm{I}-\mathrm{T}$ & 0.169 & 0.043 & Zhang et $a l^{9}$ \\
\hline $\mathrm{SiO}_{2} / \mathrm{SnO}_{2} / \mathrm{MnPc} / \mathrm{GCE}$ & DPV & 0.147 & 0.7 & Santos et $a l^{6}$ \\
\hline$\beta \mathrm{CDSH} / \mathrm{FeTMPyP} / \mathrm{CDAuNP} / \mathrm{GCE}$ & IT & 0.1 & 0.625 & Damos et $a l^{25}$ \\
\hline Poly-L-lysine/GCE & DPV & 0.174 & 3 & Luz et $a l^{26}$ \\
\hline GNP-f-CNT/GCE & LSV & - & 3.125 & Tsai et $a l^{7}$ \\
\hline Nickel-salen/platinum electrode & $\mathrm{I}-\mathrm{T}$ & - & 0.5313 & Martin et $a l^{27}$ \\
\hline $\mathrm{RGO} / \mathrm{Ag} / \mathrm{GCE}$ & $\mathrm{I}-\mathrm{T}$ & 0.205 & 0.031 & This work \\
\hline
\end{tabular}

Table 2. The responses of common interference on the RGO/Agmodified GCE.

\begin{tabular}{lccc}
\hline $\begin{array}{l}\text { Interference } \\
\text { species }\end{array}$ & $\begin{array}{l}\text { Response } \\
\text { ratio (\%) }\end{array}$ & $\begin{array}{c}\text { Interference } \\
\text { species }\end{array}$ & $\begin{array}{c}\text { Response } \\
\text { ratio (\%) }\end{array}$ \\
\hline $\mathrm{Na}^{+}$ & 2.14 & $\mathrm{NO}_{3}^{-}$ & 3.52 \\
$\mathrm{Mg}^{2+}$ & 3.22 & $\mathrm{SO}_{4}^{-}$ & 2.07 \\
$\mathrm{Cu}^{2+}$ & 1.21 & $\mathrm{AA}$ & 1.55 \\
$\mathrm{NH}_{4}^{+}$ & 0.87 & $\mathrm{UA}$ & 3.69 \\
$\mathrm{Fe}^{3+}$ & 0.66 & Glucose & 2.11 \\
\hline
\end{tabular}

additions of DO at RGO/Ag nanocomposite-modified GEC. The profile suggests that the $\mathrm{RGO} / \mathrm{Ag}$ nanocompositemodified GCE responds rapidly after the addition of DO and attains a steady-state current within $5 \mathrm{~s}$. A linear relationship between the current response and the DO concentrations was observed in the range from 1 to $120 \mu \mathrm{M}$ with a correlation coefficient of 0.997 . The sensitivity and detection limit was $0.205 \mu \mathrm{A} \mu \mathrm{M}^{-1}$ and $0.031 \mu \mathrm{M}$, respectively. The comparative study (table 1) indicates that the proposed sensor could be applied for detecting the DO content sensitively.

The repeatability of proposed DO sensor was tested by five different RGO/Ag nanocomposite-modified GCEs towards $50 \mu \mathrm{M}$ DO. The RSD of current responses was $4.12 \%$, suggesting an acceptable reproducibility of the proposed fabrication method. The repeatability of the proposed sensor was investigated by eight successively detections of $50 \mu \mathrm{M}$ DO. The RSD of current responses was $6.22 \%$, indicating a good reproducibility. The effects of common interference species on proposed DO sensor has also been investigated. In total, $0.5 \mathrm{mM}$ of $\mathrm{Na}^{+}, \mathrm{Mg}^{2+}, \mathrm{Cu}^{2+}, \mathrm{NH}_{4}^{+}, \mathrm{Fe}^{3+}, \mathrm{NO}_{3}^{-}, \mathrm{SO}_{4}^{-}, \mathrm{AA}$, $\mathrm{UA}$ and glucose was added into $50 \mu \mathrm{M}$ DO during the amperometric test at the applied potential of $-0.26 \mathrm{~V}$. As shown in table 2, the observed influences are less than $4 \%$. Therefore, the fabricated DO sensor can tolerate high concentrations of interfering species.

\section{Conclusion}

This paper demonstrated that a RGO/Ag nanocomposite was synthesized by the simple galvanic displacement method using $\mathrm{GO}, \mathrm{AgNO}_{3}$ and $\mathrm{Cu}$ foil as raw materials. The synthesized $\mathrm{RGO} / \mathrm{Ag}$ nanocomposite was characterized by UV-vis spectroscopy, Raman spectroscopy, XRD and SEM. The RGO/Ag nanocomposite-modified GCE was studied for the analytical determination of DO in aqueous solutions. The RGO/Ag-modified GCE showed a high current response with a positive reduction potential $(-0.26 \mathrm{~V})$ when compared to the reduction on the bare GCE- and RGOmodified GCE. Under optimized conditions, the detection limit and sensitivity of the proposed DO sensor are $0.031 \mu \mathrm{M}$ and $0.205 \mu \mathrm{A} \mu \mathrm{M}^{-1}$, respectively. The proposed DO sensor also exhibited excellent repeatability, reproducibility and anti-interference ability.

\section{References}

1. Oudot C, Gerard R, Morin P and Gningue I 1988 Limnol. Oceanogr. 33146

2. Suzuki Y, Nishide H and Tsuchida E 2000 Macromolecules 33 2530

3. Bailey R T, Cruickshank F R, Deans G, Gillanders R N and Tedford M C 2003 Anal. Chim. Acta 487101

4. Shao X D, Liu H Y, Gao X F, Chen W Q and Song Z H 2007 Chem. Pap. 61353

5. Rahim A, Santos L S S, Barros S B A, Kubota L T and Gushikem Y 2013 Sens. Actuators B: Chem. 177231

6. Santos L S, Landers R and Gushikem Y 2011 Talanta 851213

7. Tsai T H, Yang C Y and Chen S M 2013 Int. J. Electrochem. Sci. 85250

8. Wang Y, Hosono T and Hasebe Y 2013 Microchim. Acta 180 1295

9. Zhang D, Fang Y, Miao Z, Ma M and Chen Q 2013 J. Appl. Electrochem. $\mathbf{4 4} 419$

10. Wu S, He Q, Tan C, Wang Y and Zhang H 2013 Small 91160

11. Liu C, Alwarappan S, Chen Z, Kong X and Li C-Z 2010 Biosens. Bioelectron. 251829

12. Stoller M D, Park S, Zhu Y, An J and Ruoff R S 2008 Nano Lett. 83498

13. Radhakrishnan S, Krishnamoorthy K, Sekar C, Wilson J and Kim S J 2014 Appl. Catal. B: Environ. 148-149 22

14. Zhang D, Fang Y, Miao Z, Ma M, Du X, Takahashi S, Anzai J-I and Chen Q 2013 Electrochim. Acta 107656

15. Li B, Liu T, Wang Y and Wang Z 2012 J. Colloid Interface Sci. 377114 
16. Wang X, Zhi L, Tsao N, Tomović Ž, Li J and Müllen K 2008 Angew. Chem. Int. Ed. 472990

17. Fan Z-J, Kai W, Yan J, Wei T, Zhi L-J, Feng J, Ren Y-M, Song L-P and Wei F 2010 ACS Nano 5191

18. Li X, Wang Q, Zhao Y, Wu W, Chen J and Meng H $2013 \mathrm{~J}$. Colloid Interface Sci. 41169

19. Wang M Y, Shen T, Wang M, Zhang D and Chen J 2013 Mater. Lett. 107311

20. Bello A, Fabiane M, Dodoo-Arhin D, Ozoemena K I and Manyala N 2014 J. Phys. Chem. Solids 75109

21. Guascito M R, Chirizzi D, Picca R A, Mazzotta E and Malitesta C 2011 Mater. Sci. Eng. C 31606
22. Glasspool W and Atkinson J 1998 Sens. Actuators B: Chem. 48308

23. Demarconnay L, Coutanceau C and Léger J M 2004 Electrochim. Acta 494513

24. Kongkanand A and Kuwabata S 2003 Electrochem. Commun. 5133

25. Damos F S, Luz R C, Tanaka A A and Kubota L T 2010 Anal. Chim. Acta 664144

26. Luz R, Damos F S, Tanaka A A and Kubota L T 2006 Sens. Actuators B Chem. 1141019

27. Martin C S, Dadamos T R L and Teixeira M F S 2012 Sens. Actuators B: Chem. 175111 